\title{
A COMISSÃO PAPE/PBP: DESAFIOS E DESDOBRAMENTOS NO CAMPO DA ASSISTÊNCIA ESTUDANTIL
}

\author{
THE PAPE/PBP COMMISSION: CHALLENGES AND DEVELOPMENTS IN THE \\ FIELD OF STUDENT ASSISTANCE
}

\author{
Ana Carolina Gonçalves da Silva Santos Moreira ${ }^{1}$ \\ Elisa Maria Andrade Brisola ${ }^{2}$
}

\begin{abstract}
RESUMO: O texto apresenta os desdobramentos e desafios das ações implementadas pelas assistentes sociais que atuam na Comissão PAPE/PBP da Pró-Reitoria de Assuntos Estudantis da Unifesp. O objetivo que instigou a realização deste artigo foi destacar o trabalho das assistentes sociais desta Comissão acerca das demandas estudantis. As entrevistas foram realizadas com todas as profissionais envolvidas na referida comissão por meio da metodologia da História Oral. O texto estrutura-se a partir de breve histórico das ações de assistência estudantil nesta Universidade, seguido de síntese das questões que permeiam o trabalho profissional da equipe que compõem a Comissão, com ênfase nas demandas estudantis, no trabalho multiprofissional e nos desafios que a política de assistência estudantil impõe às(aos) trabalhadoras(es) deste campo. Os resultados percebidos estão relacionados com os rebatimentos da contrarreforma educacional, que se consolidam na redução de recursos para as universidades, impactando de diversas formas a realização das ações.
\end{abstract}

Palavras-chave: Trabalho do Assistente Social. Assistência Estudantil. Direito à Permanência

\begin{abstract}
The text presents the developments and challenges of the actions implemented by the social workers who work in the PAPE/PBP Commission of the Dean of Student Affairs of Unifesp. The objective that instigated the realization of this article was to highlight the work of the social workers of this Commission regarding student demands. The interviews were conducted with all professionals involved in this commission through the Oral History methodology. The text is structured from a brief history of student assistance actions at this University, followed by a synthesis of the issues that permeate the professional work of the team that makes up the Commission, with emphasis on student demands, multiprofessional work, and the challenges that student assistance policy poses to female workers in this field. The results perceived are related to the repercussions of educational counter-reform, wich are consolidated in the reduction of resources for the universities, impacting in several ways the realization of the actions.
\end{abstract}

Keywords: Social Worker's Job. Student Assistance. Right to Permanence

\footnotetext{
${ }^{1}$ Assistente social mestra, vinculada ao Núcleo de Apoio ao Estudante do campus São José dos Campos da Universidade Federal de São Paulo - Unifesp. E-mail: carolina.moreira@unifesp.br.

2 Assistente social, professora doutora na Universidade de Taubaté - Unitau. E-mail: elisabrisola@gmail.com
} 


\section{CONSIDERAÇÕES INICIAIS}

Muitas transformações ocorreram na universidade pública no que se refere à assistência estudantil a partir da vinculação das instituições ao Programa de Apoio a Planos de Reestruturação e Expansão das Universidades Federais (REUNI) ${ }^{3}$ e ao ingresso pelo Sistema de Seleção Unificada (SISU) ${ }^{4}$ : um novo perfil de estudante, cada vez mais representativo da sociedade, que demanda tanto a qualidade e excelência da formação quanto reais condições de permanência, principalmente às(aos)que se encontram em situação de vulnerabilidade socioeconômica. O profissional de Serviço Social tem participado dos processos de ampliação destes direitos e da sua consolidação nestes espaços educacionais.

Este texto pretende apresentar um recorte da realidade do trabalho do assistente social,realizado no âmbito da assistência estudantil em uma universidade federal. É fruto da dissertação de mestrado ${ }^{5}$ (MOREIRA, 2017), que abordou a operacionalização dos programas de assistência estudantil na Universidade Federal de São Paulo - UNIFESP. Partindo do ponto de vista das profissionais que os operacionalizam, este texto pretende contribuir com a análise do trabalho na assistência estudantil, com ênfase nas questões cotidianas que abarcam essa realidade.

O campo empírico ao qual este artigo está vinculado é a Universidade Federal de São Paulo, em sua Pró-reitoria de Assuntos Estudantis. Esta Pró-reitoria centraliza as ações de assistência estudantil da Universidade e, entre elas, a Comissão PAPE/PBP ${ }^{6}$. A Comissão é formada pelas oito assistentes sociais que trabalham na Reitoria (uma delas) e nos campi (as demais), além do/a coordenador/a. As assistentes sociais lotadas nos campi são vinculadas aos Núcleos de Apoio ao Estudante (NAE), presente em todos os sete campi da Universidade, que,

\footnotetext{
${ }^{3}$ O REUNI é um programa do Governo Federal instituído pelo Decreto no 6.096, de 24 de abril de 2007, que tem por objetivo ampliar o acesso e a permanência na Educação Superior, proporcionando condições para que as universidades federais promovam expansão física, acadêmica e pedagógica. Disponível em: http://reuni.mec.gov.br/o-que-e-o-reuni.

${ }^{4}$ O Sistema de Seleção Unificada - SISU é o sistema informatizado do Ministério da Educação - MEC em que instituições públicas de ensino superior oferecem vagas a candidatos selecionados e classificados pelo Exame Nacional do Ensino Médio - ENEM.

${ }_{5}$ Dissertação disponível em: https://mpemdh.unitau.br/wp-content/uploads $/ 2015 /$ dissertacoes/mdh/AnaCarolina-Goncalves-da-Silva-Santos-Moreira.pdf. Acesso em 25/01/2021.

${ }^{6} \mathrm{~A}$ Comissão PAPE/PBP constitui-se de um grupo de trabalho permanente formado pelas assistentes sociais vinculadas à assistência estudantil da Universidade Federal de São Paulo, com o objetivo de elaborar critérios, metodologia de análise e atribuição de auxílios, entre outras ações, tal como preconiza o PNAES (parágrafo $2^{\circ}$ do artigo $3^{\circ}$ do Decreto $\mathrm{n}^{\circ}$ 7.234, de 19/07/2010). Informações disponíveis em: https://www.unifesp.br/reitoria/prae/institucional/prae/comissoes/objetivos-comissao-avalicao. Acesso em $25 / 01 / 2021$.
} 
por sua vez, têm por objetivo prestar atendimento nas questões que envolvem a permanência estudantil, entre elas, os auxílios. Das oito profissionais participantes da Comissão, sete foram entrevistadas. Para garantir o sigilo que tal estudo requer, o nome delas foi substituído por nomes de brasileiras que marcaram nossa história por suas lutas. Uma oportunidade de trazer visibilidade às mesmas. A escolha dos nomes se deu por afinidade.

Considerando os demais estudos já publicados sobre o tema, este texto justifica-se por propor uma reflexão acerca do trabalho profissional junto a este campo. De modo especial, apresenta-se alguns dos resultados encontrados na referida pesquisa, considerando o contexto no qual o trabalho é realizado, destacando-se as contribuições das profissionais que participaram deste estudo.

Quanto à sua estrutura, o texto apresenta algumas considerações sobre a Universidade e seus desafios em relação à assistência estudantil; em seguida, demonstra a principal atividade demandada das assistentes sociais neste espaço profissional: o estudo socioeconômico e, por fim,traz algumas reflexões sobre o trabalho multiprofissional nos NAEs, frente às demandas estudantis. Os resultados foram apreendidos por meio da contextualização do cotidiano e de fundamentação teórica sobre o real, em um processo de triangulação. Do ponto de vista do método, utilizou-se o método marxiano, que permite ao pesquisador a compreensão da totalidade e contradições dos fenômenos estudados.

Quanto à metodologia optou-se pela História Oral, na medida em que privilegia ouvir os indivíduos pertencentes a segmentos sociais geralmente excluídos da história oficial, deixando seus registros e os do grupo social ao qual pertencem para análises futuras (CASSAB; RUSCHEINSKY, 2004, p. 12). Uma das especificidades desta metodologia e um dos motivos de sua escolha para a condução deste estudo decorre da intencionalidade do pesquisador em produzir documentos históricos, já que este participa da produção do documento de forma crítica e concomitante à realização das entrevistas (CASSAB; RUSCHEINSKY, 2004, p.13). Considerando que a pesquisadora é também membro da equipe, o método demonstrou-se adequado.

\section{A UNIVERSIDADE E OS DESAFIOS APRESENTADOS PELA ASSISTÊNCIA ESTUDANTIL}


A estrutura das universidades federais passou por transformações ao longo dos últimos dez anos, desde a publicação do Decreto n 7.234, de 19 de julho de 2010 (PNAES Plano Nacional de Assistência Estudantil). Com a publicação deste Decreto, as universidades passaram a readequar seus serviços para atender de forma mais sistematizada estudantes com vulnerabilidades socioeconômicas.

$\mathrm{Na}$ universidade em referência, foram criados a partir de 2010 órgãos multiprofissionais de apoio aos estudantes em cada um de seus campi, vinculados politicamente à Pró-Reitoria de Assuntos Estudantis - PRAE e administrativamente à direção acadêmica de cada campus. Estes órgãos foram denominados Núcleo de Apoio ao Estudante - NAE e são compostos por servidores técnico-administrativos de diversas áreas, tais como Saúde, Educação e Serviço Social. Buscam efetivar a política de assistência estudantil deliberada pelo Conselho de Assuntos Estudantis desta universidade, seguindo, desta forma, as diretrizes definidas pelo Ministério da Educação no que tange ao PNAES. Neste mesmo ano, as assistentes sociais lotadas nos NAEs perceberam a necessidade de reunir-se em um grupo de trabalho para a realização das atividades voltadas aos auxílios, iniciando os trabalhos da atual Comissão PAPE/PBP.

A partir daí, as assistentes sociais passaram a atuar de modo concomitante nos NAEs (com as equipes multiprofissionais) e na Comissão (com as assistentes sociais dos outros campi e Reitoria). Esta formação favoreceu a implementação de um programa de auxílios que respondeu às demandas advindas da nova configuração da universidade, percebidas pela instituição e delegadas como "tarefa" a essa Pró-Reitoria, por meio do decreto PNAES. A este grupo de trabalho permanente denominou-se inicialmente "Comissão PAPE", utilizando a sigla do programa de auxílio vigente no período de sua constituição (em 2010 havia apenas um programa, o PAPE: Programa de Auxílio Permanência). A partir da publicação da Portaria que criou o Programa de Bolsa Permanência ${ }^{7}$ para estudantes de graduação de instituições federais de ensino superior, a PRAE alterou a denominação de seu programa original para "PAPE: Programa de Auxílio Para Estudantes" e adicionou a sigla sugerida pelo novo programa, de

\footnotetext{
${ }^{7}$ O Programa Bolsa Permanência - PBP foi estabelecido pela Portaria Ministerial no 389 em 2013 pelo MEC com o objetivo de conceder bolsas para estudantes indígenas, quilombolas e com vulnerabilidade socioeconômica. O valor era fixado e as regras distintas do Decreto PNAES. Com o passar do tempo, os estudantes com vulnerabilidade socioeconômica deixaram de ser atendidos pelo PBP, permanecendo o benefício a estudantes indígenas e quilombolas, o que diminuiu consideravelmente o número de atendidos por este Programa nesta Universidade. Mais informações em: http://portal.mec.gov.br/programa-bolsa-permanencia. Acesso em $27 / 01 / 2021$.
} 
modo a ampliar a atuação desta Comissão para os dois programas vigentes. Desde então, a Comissão passa a chamar-se "Comissão PAPE/PBP” e a atuar em ambos os programas.

O resultado do trabalho desta Comissão foi a elaboração de um programa que abarcou critérios, instrumentos de análise e pesquisas, fluxos, instrumentos que permitiram a caracterização do perfil e seu atendimento no escopo das prioridades preconizadas no PNAES, a saber: moradia estudantil, alimentação, transporte, atenção à saúde, inclusão digital, cultura, esporte, creche, apoio pedagógico e acesso, participação e aprendizagem de estudantes com deficiência, transtornos globais do desenvolvimento e altas habilidades e superdotação (BRASIL, 2010).

Atualmente essa Comissão permanece com sua formação inicial (assistentes sociais dos NAEs, Reitoria e coordenação), em caráter contínuo, conduzindo as ações em formato de grupo de trabalho. Realizam análises de casos, aprimoramento de critérios e subsidiam a PRAE em questões relativas à assistência estudantil.

Alguns desafios se apresentam no cotidiano destas profissionais, que vão desde o número limitado de servidores públicos atuantes nesta Universidade, em especial nos campide extensão (localizados nos municípios da Grande São Paulo, Vale do Paraíba e Baixada Santista); passando pelo orçamento destinado a esta Pró-reitoria, que é insuficiente para dar conta de todas as demandas que envolvem a permanência estudantil, incluindo os auxílios; as ações no campo educativo são prejudicadas, pois a maior demanda é por análises socioeconômicas, dificultando as outras ações interventivas, entre outras dificuldades. Adiante destaca-se alguns desses entraves e como as profissionais lidam com as limitações cotidianas.

\section{O ESTUDO SOCIOECONÔMICO COMO FRENTE DE TRABALHO PARA O SERVIÇO SOCIAL}

As demandas e requisições sociais que se apresentam aos assistentes sociais expressam a dinâmica das relações sociais presentes na sociedade, ou seja, são forças provenientes tanto do movimento do capital quanto dos direitos, valores e princípios oriundos da classe trabalhadora. Particularmente, o Serviço Social se encontra organicamente vinculado às 
configurações estruturais e conjunturais da questão social ${ }^{8}$ e às formas de seu enfrentamento, permeadas tanto pela ação dos trabalhadores quanto do capital e do Estado (IAMAMOTO, 2009, p. 27-28).

O exercício profissional agrega um conjunto de determinações e mediações estabelecidas com distintos sujeitos sociais em sua condição de trabalhador assalariado. Estas determinações e mediações condicionam o processamento do trabalho cotidiano e o seu significado social, bem como restringem a autonomia profissional, com implicações na efetivação do projeto ético-político (IAMAMOTO, 2009).

Neste contexto, as atividades desenvolvidas pelas(os) profissionais sofrem, além das implicações relacionadas à sua condição de trabalhador assalariado, as demandas advindas das situações singulares vividas pelos indivíduos que acessam os serviços e suas famílias, grupos e segmentos sociais. O desafio se encontra no atendimento das necessidades sociais trazidas por estes e no trânsito da esfera privada para a luta por direitos, integrando o singular no coletivo e incorporando a pesquisa e o conhecimento da realidade destes sujeitos como requisitos fundamentais para o desempenho da profissão, aliadas à sensibilidade e à vontade política transformadoras (IAMAMOTO, 2009).

Esta narrativa descreve de modo sucinto a rotina de análises socioeconômicas realizadas por estas profissionais:

Dificuldade na manutenção aqui da universidade por vários fatores, principalmente pela situação de vulnerabilidade socioeconômica da família, que não tem condições de auxiliar nesse momento. Então, como eu auxilio: eu faço uma análise socioeconômica, verifico qual é a renda, qual a situação do grupo familiar, aí chego numa conclusão se é perfil para receber o auxílio ou não (Tarsila $\left.{ }^{9}\right)$.

As análises são realizadas caso a caso com o objetivo de obter o perfil de vulnerabilidade de cada estudante solicitante para então inseri-lo em um dos programas disponíveis. Os estudos socioeconômicos realizados pelas assistentes sociais são parte

\footnotetext{
${ }^{8}$ Marilda Iamamoto aponta a definição de questão social como expressão das desigualdades econômicas, políticas e culturais das classes sociais, acentuadas a partir do retraimento do Estado em suas ações. Estas desigualdades são agravadas por disparidades de gênero, características étnico-raciais e regionais, que limitam o acesso aos bens e a riqueza social a segmentos da sociedade civil. Destaca que neste "terreno de disputas" é que trabalham os assistentes sociais (IAMAMOTO, 2014).

${ }^{9}$ Tarsila do Amaral (1886-1973) foi pintora e desenhista paulista, participou do movimento de intelectuais modernista.
} 
intrínseca da ação profissional. A Lei n 8.662, de 07 de junho de 1993, que dispõe sobre o exercício da profissão apresenta esta ação como competência profissional.

Neste particular, estas profissionais têm por atribuição a realização dos estudos socioeconômicos para a concessão dos auxílios aos estudantes que solicitam e são identificados em um dos níveis de perfil de vulnerabilidade estabelecidos ${ }^{10}$. Esta atividade ocorre no âmbito dos Núcleos de Apoio ao Estudante, em uma primeira fase, eno escopo da Comissão PAPE/PBP, em uma segunda fase. Na primeira fase, a profissional recebe os documentos e procede à análise socioeconômica, utilizando os instrumentos necessários. Caso haja dúvidas com relação ao perfil do estudante, a profissional leva o caso para discussão no âmbito da Comissão, sendo esta a segunda fase da análise.

Além das referidas análises, as atividades na Comissão contemplam ainda a preparação dos editais anuais e a sua divulgação, os estudos socioeconômicos, a discussão e revisão de metodologias, sempre de modo compartilhado.

Regina Mioto (2009, p. 485) esclarece, que os estudos socioeconômicos são "ações significativas no processo de efetivação, garantia e ampliação dos direitos fundamentais e no enfrentamento das expressões da questão social." A finalidade imediata dos estudos socioeconômicos é a emissão de um parecer, e, de modo mais ampliado, a obtenção e análise de dados sobre a população atendida (condições econômicas, políticas, sociais e culturais), subsidiar o planejamento e a gestão dos serviços e a reformulação ou a formulação de políticas sociais (MIOTO, 2009).

Para a realização dos estudos socioeconômicos, são utilizados instrumentos como a entrevista, a observação, a reunião, a visita domiciliar e a análise de documentos pertinentes à situação determinada. Todos estes instrumentos são criados e recriados mediante os objetivos e exigências da ação profissional e são fundamentais para o conhecimento da realidade. $O$ produto da análise é um documento final, o parecer, que leva em consideração os dados da realidade, o marco teórico-metodológico e o conhecimento da área, das legislações pertinentes e de outros estudos relacionados (MIOTO, 2009).

Maria Inês Graciano e Neide Lehfeld (2010, p. 177) entendem o instrumental como o conjunto articulado de instrumentos e técnicas que permitem a operacionalização profissional, segundo uma visão crítica da realidade e o uso de habilidade e criatividade:

\footnotetext{
10 Informações disponíveis nos links:http://unifesp.br/reitoria/prae/programas/programas/pape-e$\mathrm{pbp} / \mathrm{pape}, \mathrm{http}: / /$ unifesp.br/reitoria/prae/programas/programas/pape-e-pbp/pbp http://unifesp.br/reitoria/prae/programas/programas/pape-e-pbp/programa-bolsa-permanencia-pbp-etnias.
} 
[...] $O$ instrumental não é nem o instrumento nem a técnica tomados isoladamente, mas ambos, organicamente articulados em uma unidade (entrevista/relatório, visita, reunião, observação participante etc.), produto desta visão concebida. É, portanto, o instrumental, por excelência, uma categoria relacional e abrange não só o campo das técnicas como também conhecimentos, métodos e habilidades. É uma categoria que se constrói a cada momento, a partir de finalidades da ação que se vai desenvolver e dos determinantes históricos, políticos, sociais e institucionais a ela referidos.

As outras demandas citadas pelas profissionais entrevistadas estão relacionadas aos problemas de saúde ou emocionais, que são direcionados aos profissionais de saúde dos NAEs. Casos em que são necessários encaminhamentos, e são encaminhados para os núcleos de atendimento da universidade (vinculados às Escolas de Medicina e Enfermagem), para a rede assistencial de cada município, para serviços-escola de universidades privadas ou para a rede de atendimento particular (caso os estudantes tenham convênio próprio).

\section{AS DEMANDAS ESTUDANTIS E O TRABALHO MULTIPROFISSIONAL NOS NAES}

Segundo Ortiz (2011, p. 195), a atuação interdisciplinar consiste na "interlocução horizontal entre os diversos saberes e práticas, sem desconsiderar as particularidades de cada profissão, nem a natureza da contribuição de cada um dos sujeitos profissionais envolvidos." Segundo a autora,articular as relações de modo horizontalizado nas equipes é um desafio.

Esta questão é trazida pela profissional Celina: “[...] ainda existe uma divisão entre o Serviço Social e Saúde, mas estamos caminhando e tentando trabalhar como uma equipe multidisciplinar [...]". Este campus também apresenta uma equipe praticamente completa, com profissionais (um ou dois) das áreas do Serviço Social, Psicologia e Saúde.

Como o NAE funciona doze horas seguidas, a ideia é que o estudante possa ser acolhido por qualquer profissional do setor, para depois a equipe discutir qual o encaminhamento e qual profissional ficará responsável pelo atendimento. Por exemplo, em um caso de violência sexual ou violência contra a mulher qualquer profissional faz o acolhimento do estudante e o encaminha ao psicólogo, [...] e os dois profissionais ficam como referência para $\mathrm{o}$ atendimento ao estudante $[\ldots]\left(\right.$ Celina $\left.^{11}\right)$.

11 Celina Guimarães Viana (1890-1972) foi professora e a primeira eleitora brasileira. O Estado do Rio Grande do Norte, onde nasceu, foi o primeiro do país que aboliu a distinção entre os sexos para suas eleições. 
Este NAE, particularmente, atende ao maior número de estudantes de graduação matriculados. Apresenta a maior demanda, tanto por atendimentos para análises socioeconômicas, quanto de questões de conflito e violência. A profissional ressalta que a equipe completa é essencial para o bom andamento dos trabalhos. Apesar disso, relata que o compartilhamento das atividades entre os profissionais ainda é precário:

As questões referentes aos auxílios ficam exclusivamente a cargo do Serviço Social. São poucos os profissionais da equipe de trabalho que se dispõem a acolher o estudante em um primeiro atendimento, explicando sobre o programa e tirando dúvidas. Algo que todos os profissionais estão capacitados a fazer [...] (Celina).

Segundo Ortiz (2011), para a realização das atividades nas equipes interdisciplinares é imprescindível distinguir as particularidades do papel profissional diante dos demais profissionais. A autora ressalta que muitas vezes o campo social é compreendido por outros profissionais como uma abstração, sem conteúdo histórico, ou meramente cultural, cabendo aos assistentes sociais a construção e a sistematização de projetos e ações coletivas que contemplem as demandas. A autora destaca aspectos da profissão que possibilitam estas ações, tais como a formação generalista, a capacidade de analisar a conjuntura, o reconhecimento de possíveis aliados para a implementação das ações, a realização de conexão da demanda trazida pelos usuários com a dinâmica estrutural e sócio histórica mais ampla, a associação da demanda a elementos da formação social brasileira e latino-americana e a relação existente na sociedade de classes que restringe escolhas e possibilidades dos sujeitos.

Ortiz (2011) destaca algumas características do perfil profissional que contribuem para uma atuação interdisciplinar, quais sejam um profissional crítico, criativo, competente, comprometido, que não rebaixa ou dilui seu saber, papel ou intervenção diante dos demais profissionais. Segundo ela, o trabalho interdisciplinar deve ser orientado pela perspectiva da totalidade, com garantia do sigilo profissional e com a criação de espaços democráticos e plurais no interior das equipes.

Porém, a universidade, assim como todo o setor público da Educação Superior, enfrenta a precarização nas contratações de novos servidores advindas da contrarreforma educacional $^{12}$, impactando diretamente na atenção ao estudante que cada um dos Núcleos

\footnotetext{
12 Segundo Behring (2009, p. 71-72), a contrarreforma consiste em certas escolhas políticas dos governos em, partindo de novas relações com os grupos mundiais, ocupar um lugar cada vez mais subordinado, restringindo-se
} 
pode oferecer. Na prática, o número de servidores nas equipes varia de campus para campus, e depende de articulação das Direções de cada unidade e de vagas junto ao Ministério da Educação - MEC.

Esta profissional relata também que o NAE neste campus é acionado por motivos diversos, inclusive alguns que não são da competência deste Núcleo, mas que as demais instâncias acadêmicas do campus entendem que deve ser encaminhado ao NAE: "Qualquer demanda do campus vai para o NAE, e especificamente para a assistente social, mesmo extrapolando os limites da nossa atuação [...]” (Celina). Em relação a esta situação, reflete que falta diálogo entre a direção e os estudantes, cabendo ao NAE favorecer a escuta e a abertura ao diálogo.

A assistente social Maria Quitéria relatou, além das situações já citadas, circunstâncias de preconceito vivenciadas por estudantes, baixa autoestima e demais intercorrências que envolvem questões de saúde mental. Os casos que envolvem preconceito, citados pela profissional, são relativos aos grupos étnicos e minorias que cada vez mais estão representados no ambiente universitário, quais sejam as pessoas com deficiência, estudantes oriundos de países africanos (por intermédio de programas de intercâmbio), questões de gênero e homoafetividade, entre outros grupos. Esta profissional relata inclusive a importância de grupos de discussão entre os próprios estudantes acerca destes temas, os coletivos.

A respeito dos conflitos vivenciados pelos estudantes LGBTQ+, esta profissional entende que são oriundos de seu reconhecimento e identificação, que ocorrem no período que coincide com, ou é propiciado pelo ingresso na universidade. Segundo este relato, os estudantes procuram o NAE para buscar ajuda e apoio neste processo de amadurecimento, muitas vezes não encontrados em suas famílias.

Como forma de dar vazão e/ou atendimento a esta e outras questões relacionais, a profissional busca nos coletivos e outras organizações estudantis o contato permanente, entendendo que o NAE tem papel articulador, não centralizador:

Eu acho que o nosso papel [...] de quem está dentro da instituição, dentro dos programas em si é isso: é poder propiciar que nosso público-alvo tenha

a cobrir custos de infraestrutura, aplicar incentivos fiscais, garantir escoamento da produção e institucionalizar processos de liberalização e desregulamentação em nome da competitividade e da atratividade. Em contrapartida, observam-se as desregulamentações e flexibilizações nas relações de trabalho, nas privatizações e no impacto nas condições de vida das "maiorias", em nome da adaptação a esta contrarreforma do Estado. 
o conhecimento de como funciona os seus direitos e se apoderem disso. É fazer essa interlocução[...] (Maria Quitéria ${ }^{13}$ ).

A assistente social Carolina de Jesus descreve suas demandas a partir do trabalho exercido no NAE do maior campus em número de estudantes de graduação (mesmo local de trabalho da profissional Celina). Segundo ela, a demanda por auxílios é tão grande quanto as demais demandas que surgem em paralelo:

É um campus que apresenta uma diversidade de demandas significativas. Eu acho que por ser um campus cuja grande maioria dos cursos são na área de educação, a gente tem um número maior de estudantes com um perfil próximo ao perfil da assistência [social], estudantes que apresentam algum tipo de elemento ou fator de vulnerabilidade, dentro de um contexto familiar, contexto socioeconômico. A gente sabe que [...] os cursos de licenciatura ainda são os cursos com estudantes da periferia, os estudantes mais pobres ainda procuram, porque acham que é o curso que eles vão ter acesso e que vai possibilitar a eles emprego de imediato [...] (Carolina de Jesus $\left.^{14}\right)$.

Apesar de a universidade pública ser a opção de muitos jovens com baixa renda no Brasildevido ao não pagamento de mensalidades, este público ainda é minoria na maior parte dos campi desta universidade. Neste campus, especificamente, há um dado diferente dos demais, apontado na pesquisa com os estudantes ingressantes em 2011. Mais de 64\% destes indicou ter renda até cinco salários mínimos, única unidade desta universidadecom este indicativo.

As demais questões apontadas pela profissional presentes no cotidiano deste Núcleo estão relacionadas à questão racial, de gênero, conflitos (relações interpessoais entre estudantes e entre estudantes e demais membros da comunidade acadêmica), dificuldades de acompanhamento nos estudos, por defasagem no ensino médio, entre outras questões, comuns aos demais NAEs. Apontamentos também foram feitos com relação à moradia, ao transporte, o impacto do trabalho no cotidiano acadêmico dos estudantes do período noturno e ausência de acompanhamento pedagógico.

A mediação aparece, para esta profissional, como as reconstruções que estruturam a dinâmica das ações, trabalhadas no âmbito das representações da população usuária, tal como definida por Pontes (1995), utilizando estratégias que superam a singularidade, articulando as forças e os sujeitos que se apresentam:

\footnotetext{
${ }^{13}$ Maria Quitéria de Jesus Medeiros (1792-1853) foi a primeira militar brasileira a combater no país. É patrona dos oficiais do exército e conhecida como a Joana D'Arc brasileira.

${ }^{14}$ Carolina Maria de Jesus (1914-1977) foi moradora de uma favela na capital de São Paulo onde trabalhava como catadora. Ficou conhecida por registrar o cotidiano da comunidade em cadernos encontrados no lixo. Foi uma das primeiras e mais importantes escritoras negras brasileiras.
} 
É muita coisa que a gente tem dentro da universidade, são muitas demandas. Desde um problema localizado, como um estudante que entra com um machado na universidade e a gente tem que trabalhar essa relação desse machado para esse estudante, dessa religião que ele aceita; a uma coisa maior, de estudantes que estão organizados para mobilizar uma greve, e aí tem que ser feita uma mediação, uma intervenção para saber o que é possível dialogar para que aquilo não chegue a um momento tão extremo[...]. (Carolina de Jesus).

Segundo esta profissional, a permanência estudantil não está relacionada apenas ao benefício financeiro, mas vai além. A profissional levanta a questão da qualidade da formação, voltada para um público peculiar:

Os cursos deste campus são no vespertino e noturno somente, então há um número muito grande de estudantes trabalhadores na universidade, e essa é uma questão que a gente precisa discutir realmente. Como é que a gente está trabalhando essa permanência do estudante na universidade? Que qualidade de formação esses estudantes estão tendo [...]. E a permanência está relacionada [...] com a questão pedagógica. [é preciso] trabalhar a questão pedagógica em paralelo ao auxílio [...]. É complicado a gente trabalhar em um NAE sem pedagogo[...] (Carolina de Jesus).

A mesma profissional, na narrativa a seguir, revela limitação na atuação do profissional do Serviço Social, ao se deparar com questões que ultrapassam a possibilidade de atendimento do setor:

A assistência estudantil não foi feita exclusivamente para estudantes com uma vulnerabilidade econômica, ela é feita para todo o estudante que tenha algum tipo de vulnerabilidade na permanência na universidade, seja ela vulnerabilidade econômica e aí [tem] os auxílios, mas tem estudantes com outro tipo de vulnerabilidade, de aprendizado, de outras coisas. Então hoje o Núcleo por mais que a gente queira evoluir para... prestar esses serviços, o maior serviço é o auxílio, mas eu acho que não é por uma questão de não tentativa dos profissionais de fazer algo diferente, eu acho que é por questões de infraestrutura mesmo que a gente não tem condições de dar conta. E é essa estrutura que eu penso não somente do Núcleo, é este diálogo com os [setores] da universidade, esse compromisso que tem que ter de todos com a permanência desse estudante [...] (Carolina de Jesus).

De modo a incorporar ao trabalho profissional as dimensões universais e particulares postas pelos sujeitos, as profissionais nos trazem observações empíricas acerca do públicoalvo da assistência estudantil em seu campus, nas narrativas a seguir: 
De um modo geral, eu tenho observado, do ponto de vista socioeconômico, um público mais vulnerável em relação aos anos anteriores. A gente percebe que ao longo desses anos, com a implementação da lei de cotas, uma demanda maior de estudantes mais vulneráveis do que a gente tinha anteriormente. E não necessariamente só os cotistas são mais vulneráveis, tem estudantes que não ingressaram pelo sistema de reserva de vagas, mas que têm uma situação de vulnerabilidade bastante significativa. Eu tenho percebido ao longo desses últimos anos um agravamento da condição socioeconômica dos estudantes, não só sócio econômica, mas do ponto de vista também de acadêmico e de formação [...] (Leila $\left.{ }^{15}\right)$.

$\mathrm{O}$ aumento de estudantes que são os primeiros a ingressarem no ensino superior em suas famílias; estudantes oriundos de famílias atendidas por programas sociais; estudantes trabalhadores (principalmente os matriculados em período noturno); estudantes pais e mães; com idade acima de $24 \operatorname{anos}^{16}$ são alguns dos novos perfis dos estudantes desta universidade. Para responder a estas demandas, no que tange ao atendimento do Serviço Social, as profissionais procuram atender aos pedidos de auxílios/bolsas com a inserção de índices redutores, agravantes e atenuantes ${ }^{17}$ nas análises, considerando a condição peculiar apresentada por cada caso. Porém, há de se considerar o caráter de totalidade que estas demandas apresentam, tal como esclarece a assistente social Estamira ${ }^{18}$ :

Articular diferentes formas desse estudante também poder participar de pesquisa e extensão sendo um estudante do noturno e sendo um estudante trabalhador é uma dificuldade na construção pedagógica dos cursos. O universo acadêmico tem que começar a ter mudanças em relação a isso, a essa nova realidade de estudante trabalhador, porque acredito que cada vez vai aumentar mais, independente do curso que a pessoa escolha, acho que deveria ter uma mudança necessária [...] (Estamira).

\footnotetext{
${ }^{15}$ Leila Diniz (1945-1972) foi atriz e reconhecida por suas atitudes de enfrentamento à repressão contra as mulheres em seu tempo. A ser fotografada grávida de biquíni na praia, chocou o país e chamou a atenção para a condição de subalternidade das mulheres de sua época.

${ }^{16}$ A faixa etária de 18 a 24 anos é utilizada como referência por representar o contingente populacional com adequada demanda para o ensino superior. Este norteador é utilizado por agências internacionais e, no Brasil, observa-se estudantes mais velhos nesta modalidade de ensino. Informação disponível em: https://www.revistaensinosuperior.gr.unicamp.br/artigos/acesso-ao-ensino-superior-no-brasil-equidade-edesigualdade-social\#_ftn1 Acesso em 04/10/2020.

${ }^{17}$ Os índices redutores, agravantes e atenuantes fazem parte da metodologia de análise socioeconômica desenvolvida pela Comissão, e têm relação com as condições materiais e objetivas demonstradas pela(o) estudante no momento da análise. A presença destes marcadores na análise pode diferenciar o valor de auxílio concedido a estudantes com a mesma renda per capita. Informações disponíveis no link: http://unifesp.br/reitoria/prae/programas/programas/pape-e-pbp/pape.

${ }^{18}$ Estamira Gomes de Souza (1939-2011) ficou conhecida por protagonizar um filme homônimo, lançado em 2004 com direção de Marcos Prado. Apresentava distúrbios mentais e chamava a atenção pelo discurso filosófico em contraste com a realidade de pobreza de onde vivia e trabalhava - um aterro sanitário na capital do Rio de Janeiro.
} 
Em suma, as questões cotidianas que perpassam o trabalho profissional neste campo específico estão relacionadas com a articulação entre os profissionais dos Núcleos no que tange aos atendimentos realizados; o número elevado de estudantes nos campi em relação ao de assistentes sociais e de técnicos nas equipes; a diversidade de demandas trazidas pelos estudantes, que requerem respostas profissionais e institucionais; os rebatimentos da contrarreforma educacional, que se consolidam na redução de recursos para as universidades ${ }^{19}$, gerando tensões entre o público atendido, as equipes e a gestão; a necessária articulação entre estudantes, técnicos e gestão, que demanda mediação e diálogo; a escassez de profissionais, como por exemplo a/o pedagoga/o, imprescindível para articulação de respostas às questões educacionais trazidas pelas/os estudantes; o aumento da vulnerabilidade das/dos estudantes que procuram a assistência estudantil, que muitas vezes lembra os serviços de referência da assistência social.

\section{CONSIDERAÇÕES FINAIS}

As demandas estudantis direcionadas ao profissional de Serviço Social que atua nos Núcleos de Apoio ao Estudante das universidades federais demandam respostas. O trabalho multi/interdisciplinar favorece a elaboração de caminhos e estratégias para responder a tais demandas, sejam elas de cunho social (encaminhamentos internos ou externos), questões de saúde (física ou mental), questões pedagógicas (acompanhamentos, oficinas), dificuldades de aprendizagem (envolver as coordenações de curso), atividades culturais, entre outras.

A partir da realização desta pesquisa, emergem os resultados aqui publicados, que nos trazem um retrato deste campo de trabalho e suas especificidades, bem como apresenta as demandas do público-alvo das políticas de assistência estudantil desta universidade.

Destaca-se, neste processo, o trabalho realizado na Comissão PAPE/PBP, comissão permanente de trabalho e estudos, que por meio de seu fazer cotidiano, demonstra que novas possibilidades podem ser alcançadas a partir da desvinculação de um processo burocrático

\footnotetext{
${ }^{19} \mathrm{~A}$ verba de custeio é prevista anualmente na Lei Orçamentária Anual e é utilizada para pagamento de despesas de manutenção cotidiana das universidades, tais como energia elétrica, abastecimento de água, serviços de segurança e limpeza, assistência estudantil, entre outras. Porém, este recurso tem permanecido o mesmo ano a ano, ou até mesmo reduzido, mesmo com o aumento das despesas. É liberado em parcelas, dificultando ainda mais o planejamento das universidades.
} 
reducionista de "bolsificação" da assistência estudantil, em uma perspectiva crítica, criativa e aguerrida das profissionais envolvidas neste trabalho.

\section{REFERÊNCIAS}

BEHRING, E.R. "Expressões políticas da crise e as novas configurações do Estado e da Sociedade Civil.” In: Serviço Social: Direitos Sociais e Competências Profissionais. Brasília: CFESS/ABEPSS, 2009. p. 69-86.

BRASIL. Decreto n ${ }^{\circ}$ 7.234, de 19 de julho de 2010. Dispõe sobre o Programa Nacional de Assistência Estudantil - $\quad$ PNAES. Disponível em: <http://www.planalto.gov.br/ccivil 03/ Ato2007-2010/2010/Decreto/D7234.htm>.

Acesso em 04out. 2020.

CASSAB, L. A.; RUSCHEINSKY, A. Indivíduo e ambiente: a metodologia de pesquisa da história oral. In: Biblos, Rio Grande, v. 16, p. 7-24, 2004.

GRACIANO, M. I. G.; LEHFELD, N. A. S. Estudo Socioeconômico: indicadores e metodologia numa abordagem contemporânea. In: Serviço Social \& Saúde, Campinas, v. IX, n. 9, p. 157-186, jul. 2010.

IAMAMOTO, M.V. Serviço Social em tempo de capital fetiche: capital financeiro, trabalho e questão social. 8. ed. São Paulo: Cortez, 2014.

O Serviço Social na cena contemporânea. In: Serviço Social: Direitos Sociais e Competências Profissionais. Brasília: CFESS/ABEPSS, 2009. p. 15-50.

MIOTO, R. C. Estudos socioeconômicos. In: Serviço Social: Direitos Sociais e Competências Profissionais. Brasília: CFESS/ABEPSS, 2009. p. 481-496.

MOREIRA, A. C. G. S. S. A contribuição do Serviço Social na operacionalização da política de assistência estudantil na UNIFESP: o olhar da Comissão PAPE/PBP. 2017. 208f. Dissertação (Mestrado em Desenvolvimento Humano) - Universidade de Taubaté.

ORTIZ, F. da S. G. Interdisciplinaridade e Assistência Social. In: O trabalho do/a Assistente Social no Suas:seminário nacional. Brasília: CFESS, 2011. p. 188-199.

PONTES, R. N. Mediação e Serviço Social. São Paulo: Cortez, 1995. 